\title{
MATERIAL AND ELECTROMAGNETIC PROPERTIES OF FARADAY SHIELDS FOR ION CYCLOTRON HEATING ANTENNAS*
}

\author{
D. J. Hoffman \\ W. R. Becraft ${ }^{\dagger}$ \\ F. W. Baity \\ J. B. O. Caughman ${ }^{\ddagger}$ \\ C. C. Tsai \\ Oak Ridge National Laboratory \\ P.O. Box $Y$ \\ Oak Ridge, Tennessee 37831 \\ (615) $5: 6-5282$
}

CONE $-850310--42$

\begin{abstract}
The Faraday shields for ion cyclotron antennas must transmit magnetic wayes and adsorb little rf power. To investigate these properties, we have constructed 27 Faraday shields in many configurations, including chevrons, tubes, straps, concentric rings, varıous layered shields, conventionally leafed straps, and replicas of the Faraday shieids for ASDEX, the Joint European Torus (JET), TEXTOR. and Alcator-C. We have measured the magnetic flux and observed loading at various operating resistances by using dielectric sheets or magnetic-coupled loads. Each Faraday shield effects a net change in the characteristic inductance of the antenna, resulting in a reduction of wave coupling. However, the load experienced by the antenna is not always reduced because the Faraday shieid itself acts as a load. We differentiate between these effects experimentally. The net result of the study is that the Faraday shields now in use cost up to a factor of $50 \%$ of coupling. This, of course, reduces the power handling capability by $50 \%$ as well. However, configurations exist that are easily cooled and result in a reduction of less than $5 \%$ in loading.
\end{abstract}

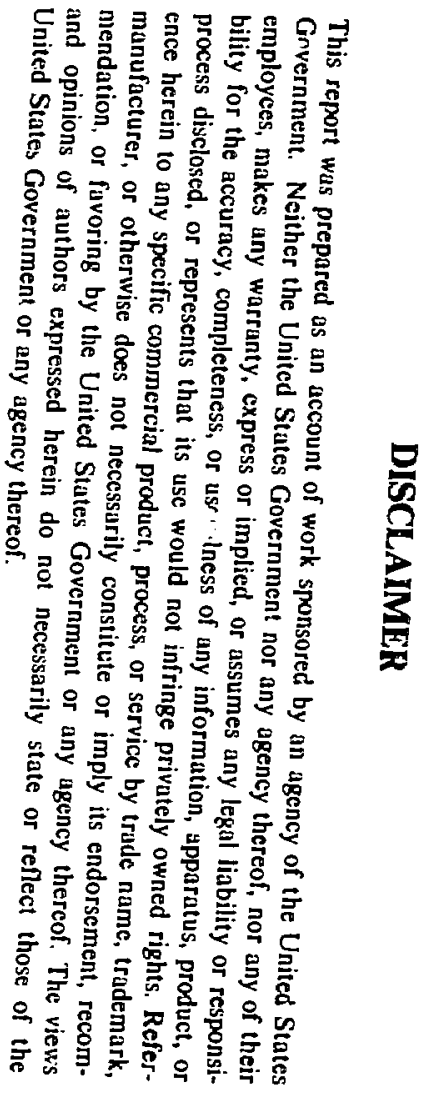

"Research spoasored by the Office of Fusion Energy, US. Department of Energy. under Contract No. DE-AC05-84OR21400 with Martin Maruetta Energy Systems, Inc.

${ }^{\dagger}$ General Electric Cumpany, Schenectady, NY 12345.

'Summer siudent, University of Illinuis, Urbana, IL $6180 \mathrm{cl}$.

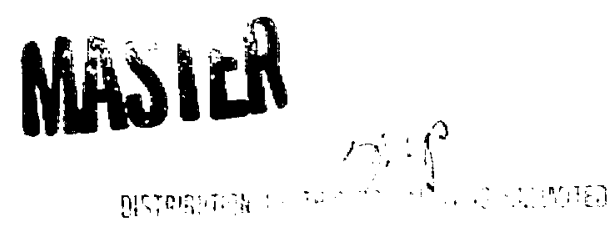




\section{INTRODUCTION}

RF power has been used quite successfully to heat plasmas in a number of fusion experiments. ${ }^{\prime}$ In particular, heating in the ion cyclotron range of frequencies (ICRF)—nominally from 20 to $100 \mathrm{MHz}$-is expected to scale favorably for use in reactor and proof-of-principle fusion experiments. ${ }^{2}$ The level of power required for present experiments such as the Tokamak Fontenay-auxRoses (TFR), the Princeton Large Torus (PLT), TEXTOR, and ASDEX ranges from 1 to $5 \mathrm{MW}$; nearterm experiments such as Doublet III-D (DIII-D), the Joint European Torus (JET), ${ }^{3}$ and JT-60 will have - 10-30 MW; reactorlike experiments will need $50 \mathrm{MW}$ or more.

The growing levels of applied power in considerably harsher environments make it necessary to improve if system efficiency while still meeting the technical demands imposed by the plasma. At about $\$ 2$ per watt for typical ICRF systems, the cost savings of even a $5 \%$ improvement is substantial in experiments such as DIII-D.

In order to optimize a system, the performance of the components of the system nust be enhanced. The purpose of this paper is to present experimental methods for measuring the electromagnetic performance of Faraday shields, to present the results of experiments on 27 Faraday shields, and to infer the effects of shields on system efficiency and the shields' ability to enable the assembly to cope with the harsh environment.

The qualities that make a "good" Faraday shield include high transmission of the desired wave component and polarization; sufficient optical opacity to protect antenna elements from the plasma; circuit characteristics that minimize voltages and maximize power through the antenna system: and the ability to withstand both high particle and energy fluxes for a reasonable component lifetime. The results of this experiment show how to obtain high wave transmission. We measure and compare opaque Faraday shields with open ones but do not demonstrate what degree of opacity is required. The circuit impact of the Faraday shield to maximize power per antenna has 
been measured for a specific geometry, but it cannot be completely resolved until plasma interactions with the Faraday shield and the antenna are incluied. Finally, we demonstrate that acceptabie configurations exist that can be easily cooled to withstand the severt plasma-material interactions.

Twenty-four Faraday shields were tested in the setup to be described. The shields are arrays of conductors (Fig. 1), with cross sections that include flat straps (5), filaments (1), chevrons (1), half-chevrons (2), tubing (4), graphite-coated tubes (8), tees (2), and dense $Z$ (1). Table I lists these shields, their types and the relevant dimensions. With the exception of one stainless steel tubing shield and the graphite-coated series, all shields were made out of copper so that the configuration (and not the material) was the item under scrutiny. Among those tested are configurations similar to those used on JET, ASDEX, and TEXTOR and to those formerly used on ELMO Bumpy Torus (EBT) and the Tandem Mirror Experiment (TMX). In general, the shape was chosen and based on present use, contribution to a data base, or expected nearterm use. In addition to the 24 listed above, 3 more shields in the Alcator-C configuration ( $\mathrm{Fig} .2$ and Table II) were tested. The geometry of the concentric rings in the Alcator-C configuration did not permit use of the same setup as the other 24 . In this case the comparisons are made with another antenna.

\section{THE TEST SETUP}

The basic setup is shown in Fig. 3. The test setup includes an antenna spaced $-8 \mathrm{~cm}$ away from nine wide sheets of resistive load (Eccossorb V060), a magnetic probe very close to the resistive lead, and a network and impedance analyzer.

The antenna geomerry in this test was a cavity antenna (Fig. 4), which is expected to be used on DIII-D. The HF 4191A impedance analyzer was used to get precise measurements of the antenna characteristics, including the lead inductance $L_{\text {lead }}$ and resistance $\eta_{\text {lead, }}$ the capacitance $C$, the strap inductance $L$, and the load resistance $r$. Once these parameters were measured, a cross-impedance could be calculated to infer the current in the main strap from the voltage at the feed point (Fig. 5). Then an HP8505 network analyzer was used to measure the magrietic probe voltage relative to an input voltage to the antenna. The net measured items included inductance at 
$1 \mathrm{MHz}$, a lower and upper resonance frequency and respective loads, and the lower resonant frequency's magnetic probe voltage over the antenna input voltage. From this we infer $I_{\text {iead }} r_{\text {lead }}, r, L, C$, and the magnetic field at the resistive sheet per unit current $(B / I)^{2}$. Figure 6 shows that the inferred antenna parameters are in good agreement with the actual measurements across the 20-MHz spectrum.

\section{RESULTS}

The Faraday shield configuration had little impact on the profile of the magnetic fields. Figure 7 shows the toroidal component of the wave as a function of position across the face of the antenna without a Faraday shield and with shield 7. These two measurements and measurements of 13 other shields show the same thing; only the amplitude is affected. Similarly, the Faraday shieid had little effect on the profile of the $B_{Z}$ component as a function of distance from the antenna (Fig. 8). It must be noted, however, that structures which substantially projected from the side walls of the cavity did slightly modify the profile in the neighborhood of the side walls.

The effect of the Faraday shield on the polarization of the wave was virtually impossible to measure in this setup. Without a Faraday shield, at $10 \mathrm{~cm}$ from the face of the antenna, the poloidal component was $-24.5 \mathrm{~dB}$ below the toroidal component. With Faraday shreld 6 . the same measurement was $-26 \mathrm{aB}$. Both toroidal signals, however, were at least $55 \mathrm{~dB}$ below the input signal. Thus, the $-80-d B$ poloidal signal levels to the network analyzer are close to the threshoid of error.

The most pronounced effects of the Faraday shield were in the observed load, magnitude of the field, and current strap inductance. Figure 9 shows the correlation of the first two as a functic: of Faraday shield. Both flux and lead resistance are normalized to no-Faraday-shield use. Included are the three Alcator-C types, although their noFaraday-snieid normaiization tactor is dif̂ferent because of the different test antenna used. Table III lists the loading, flux, and inductance as functions of the Faraday shield. 


\section{INTERPRETATION OF THE RESULTS}

The net effect of the Faraday shields was to reduce antenna coupling to the plasma. The approximate power in the system is given by

$$
P=\int H_{\bar{Z}}^{2}(k) Z(k) d A+I^{2} R_{\mathrm{FS}}+I^{2} R_{\mathrm{loss}},
$$

where $R_{\text {FS }}$ is the loss in the Faraday shield, $R_{\text {loss }}$ is the loss in the antenna structure, $H_{Z}$ is the rf magnetic field at the plasma surface, $Z$ is the effective surface impedance, and $k$ is the toroidal wave number. Since our measurements indicate little spectral alteration with Faraday shields, we treat the impedance as a constant given by plasma parameters for a given antenna in a given experiment. For comparative purposes, Eq. (1) becomes

$$
P=\left.H_{Z}^{2}\right|_{\text {surface }} Z A-I^{2} R_{\mathrm{FS}}+I^{2} R_{\text {loss }}
$$

Substituting $B_{Z}=\mu_{0} H_{Z}$ and arranging terms,

$$
P=I^{2}\left[Z \frac{A}{\mu_{0}^{2}}\left(\frac{B}{I}\right)^{2}+R_{\mathrm{FS}}+R_{\mathrm{loss}}\right] .
$$

Since $Z A / \mu_{0}^{2}$ is independent of the Faraday shield, the optimization process is maximizing $(B / I)^{2}$. Furthermore, for inductive antennas where $V=(j \omega L I)$, Eq. (3) can be transferred to

$$
I=|V|^{2}\left[\frac{1}{(\omega L)^{2}} \underset{\mu_{0}}{Z A}(B / I)^{2}+R_{\mathrm{FS}}+R_{\mathrm{loss}}\right]
$$


The obvious fact from this study is that typically used Faraday shields (e.g., JET, TEXTOR, ASDEX, and dense $Z$ types) and dense structures reduce the loading by up to $70 \%$. This, for a fixed maximum voltage, cuts the power per antenna in half. The solution to this, as implied in Fig. 8, is to move the antenna close to the plasma-at the expense of Faraday shield erosion and possible impurity introduction. We note that the tubing structures' flux transmission was typically $85 \%$ to $90 \%$, quite suitabl: for both cooling and coupling. By comparing, ather trends can be observed: thicker straps are worse than thin ones, and broader straps are worse (even at the same percentage optical transparency). For the graphite-clad tubing, increased optical transparency corresponds to an increase in flux transmission (Fig. 10). Tiers of tubing can be used to make the structure both optically opaque and if transparent.

Actual losses in the Faraday shields were all low. Notably, the lossy materials (graphite) and stainless steel had measurable but acceptable losses. The losses can be read from Fig. 9 or Table III. The difference between the observed normalized lead resistance and normalized flux is proportional to losses in the Faraday shield. The normalizing resistive factor is $-0.078 \Omega$ for the first 24 shields and $0.793 \Omega$ for the Alcator-C shields. Given our measurements of Faraday shield losses and the measurements of loading on the Alcator-C antenna without plasma, we can infer that virtually all of their free-space power coupling goes to the Faraday shield. However, with a 1- to 2-\$ plasma load, only $-3 \%$ will go to the Faraday shield.

The last important effect is the net reduction in inductance. If the power limitation of the antenna system is given by a maximum voltage, some of the decreased coupling may be partially compensated by an accompanying decrease in inductance (see Table III). The limit for decrease in inductance is a completely closed Faraday shield; $L-60 \mathrm{nh}$ in this case. Many of the Faraday shields approach this minimum while still transmitting flux to the plasma surface. For antennas where the inductance is determined largely by other metallic walls, this voltage benefit may not occur. Howsver, the Faraday shield can still be used to clamp the inductance to a fixed value, as opposed to having a nearby plasma be the controlling conductor. 


\section{CONCLUSIONS}

It is relatively straightforward to make rf-transparent Faraday shields that lend themselves to cooling and low imparity sputtering rates. Optically opaque or partially optically opaque structures exist with high transparency. However, present Faraday shields are not very transparent. They mandate either a lower power limit per antenna or placement close to the plasma. In addition, if the plasma loading is very weak, the coupling can actually increase power coupling to the Faraday shield. There can be benefits in the reduced voltages accompanying the reduction in antenna inductance. It is necessary to design the Faraday shield configuration to meet the electrical considerations. Tijis maximizes the power per antenna and the system efficiency. There are a number of these good configurations. Other considerations such as cooling, antenna protection, inductance control, and impurity reduction can be built in to these configurations.

\section{ACKNOWLEDGMENT}

We would like to thank F. Baker, R. Dixon, J. Skinner, and S. Swicegood for fabricating the Faraday shields, antennas, and test setup.

\section{REFERENCES}

1. "The Nat,onal RF Technology Research and Development Plan," CONF-820758, Oak Ridge National Laboratory (1983).

2. M. Yoshikawa and K. Tomabechi, "JT-60 Project and Its Present Status," Nucl. Technol./Fusion, 4, 299-308 (1983).

3. P. H. Rebut, "JET Progress Report," Heating in Toroidal Plasmas: Proc. 4th Int. Symp. Rome, March 1984, Vol. , p. , International School of Plasma Physics and ENEA, Varenna, Italy (1984). 
Table I. Faraday shield descriptions

\begin{tabular}{|c|c|c|c|}
\hline $\begin{array}{l}\text { Shield } \\
\text { number }\end{array}$ & Type & Description & Material \\
\hline 0 & & No Faraday shield & \\
\hline 1 & Flat strap & $\begin{array}{l}\text { 3/4-in. strap, } 1 / 4 \text {-in. gap, } \\
1 / 16 \text { in. thick }\end{array}$ & Copper \\
\hline 2 & Flat strap & $\begin{array}{l}\text { 1/2-in. strap, } 1 / 4 \text {-in. gap, } \\
1 / 16 \text { in. thick }\end{array}$ & Copper \\
\hline 3 & Flat strap & $\begin{array}{l}\text { 3/4-in. strap, 1/4-in. gap, } \\
1 / 8 \text { in. thick }\end{array}$ & Copper \\
\hline 4 & Flat strap & $\begin{array}{l}\text { 1-in. strap, 1/2-in. gap, } \\
1, \text { is in. itiis }\end{array}$ & Copper \\
\hline 5 & Flat strap & $\begin{array}{l}\text { 3/8-in. strap, 1/8-in. gap, } \\
1 / 16 \text { in. thick }\end{array}$ & Copper \\
\hline 6 & Filament & & Copper \\
\hline 7 & Dense $Z$ & $\begin{array}{l}\text { 1/2-in. straps, 0.070-in. gap. } \\
1 / 4 \text { in. depth }\end{array}$ & Copper \\
\hline 8 & 1 -tier & 3/8-in. tubes, $1 / 8$-in. gap & Copper \\
\hline 9 & I-tier & 3/8-in. tubes, $1 / 8$-in. gap & Stainless steel \\
\hline 10 & 2 -iser & 3/8-in. rubes, all gaps $1 / 8$-in. & Copper \\
\hline 11 & 3 -iier & 3/8-in. tubes, a!l gaps $1 / 8-1 n$. & Copper \\
\hline 12 & Tee & JET dimensions & Copper \\
\hline 13 & Tee & ASDEX dimensions & Copper \\
\hline 14 & Half chevron & 1/2 TEXTOR density & Copper \\
\hline 15 & Half chevron & TEXTOR dimensions & Copper \\
\hline 16 & ChevroI: & $\begin{array}{l}1 \text {-in. slats, } 1 / 8-i n . \text { gap, } 90^{\circ} \\
\text { included angle }\end{array}$ & Brass \\
\hline 17 & Graphite & $\begin{array}{l}\text { 3/8-in. tube, } 1 / 16 \text {-in. coating, } \\
\text { 1/32-in. gap }\end{array}$ & Graphite \\
\hline 18 & Graphite & $\begin{array}{l}\text { 3/8-in. tube, 1/16-in. coating. } \\
\text { 1/16-in. gap }\end{array}$ & Graphite \\
\hline 19 & Graphite & $\begin{array}{l}\text { 3/8-in. tube, } 1 / 16 \text {-in. coating, } \\
\text { 1/8-in. gap }\end{array}$ & Graphite \\
\hline 20 & Graphite & $\begin{array}{l}\text { 3/8-in. tube, } 1 / 16 \text {-in. coating, } \\
3 / 16 \text {-in. gap }\end{array}$ & Graphite \\
\hline 21 & Graphite & $\begin{array}{l}\text { 3/9-in. tube, 1/16-in. coating, } \\
1 / 4 \text {-in. gap }\end{array}$ & Graphite \\
\hline 22 & Graphite & $\begin{array}{l}\text { 3/8-in. tube, 1/16-in. coating, } \\
5 / 16 \text {-in. gap }\end{array}$ & Graphite \\
\hline 23 & Graphite & $\begin{array}{l}\text { 3/8-in. tube, } 1 / 16 \text {-in. coating, } \\
\text { 3/8-in. gap }\end{array}$ & Graphite \\
\hline 24 & Graphite & $\begin{array}{l}\text { 3/5-in. lube, } 1 / 15 \text {-in. coaling, } \\
7.16 \text {-in. gap }\end{array}$ & Graphite \\
\hline
\end{tabular}




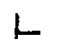

$-1-$

Table II. Alcator-C shield descriptions

\begin{tabular}{ccccc}
\hline & \multicolumn{2}{c}{ Inner ring } & \multicolumn{2}{c}{ Outer ring } \\
\cline { 2 - 5 } $\begin{array}{c}\text { Shield } \\
\text { number }\end{array}$ & $R_{i}(\mathrm{~cm})$ & $\ell_{1}(\mathrm{~cm})$ & $R_{i}(\mathrm{~cm})$ & $\ell_{2}(\mathrm{~cm})$ \\
\hline 1 & 1.588 & 2.540 & 1.905 & 0.508 \\
2 & 1.270 & 1.905 & 1.905 & 1.143 \\
3 & 1.599 & 1.905 & 1.905 & 1.143 \\
\hline
\end{tabular}


Table III. Loading, flux, and inductance of Faraday shields

\begin{tabular}{|c|c|c|c|c|}
\hline $\begin{array}{l}\text { Shield } \\
\text { number }\end{array}$ & $\begin{array}{c}\text { Normalized } \\
(B /)^{2}\end{array}$ & $\begin{array}{l}R_{\mathrm{FS}} \\
(\Omega)\end{array}$ & $\underset{(n h)}{L}$ & $\begin{array}{c}\text { Normalized } \\
\text { power }(\%)\end{array}$ \\
\hline 0 & 1.000 & & 71.95 & 100 \\
\hline 1 & 0.895 & & 69.62 & 96 \\
\hline 2 & 0.946 & & 70.85 & 98 \\
\hline 3 & 0.786 & 0.0069 & 68.34 & 87 \\
\hline 4 & 0.869 & & 69.24 & 94 \\
\hline 5 & 1.002 & & 69.57 & 107 \\
\hline 6 & 1.096 & & 71.96 & 110 \\
\hline 7 & 0.305 & $0.01 \leq 8$ & 51.48 & 42 \\
\hline 8 & 0.975 & & 68.57 & 107 \\
\hline 9 & 0.932 & 0.0214 & 68.59 & 102 \\
\hline 10 & 0.802 & & 66.62 & 93 \\
\hline 11 & 0.876 & 0.0017 & 66.51 & 102 \\
\hline 12 & 0.691 & 0.0066 & 65.33 & 81 \\
\hline 13 & 0.588 & & 65.05 & 65 \\
\hline 14 & 0.983 & & 70.10 & 103 \\
\hline 15 & 0.875 & $\cdots$ & 69.63 & 93 \\
\hline 16 & 0.547 & 0.0078 & 68.47 & 60 \\
\hline 17 & 0.520 & 0.1578 & 68.44 & 57 \\
\hline 18 & 0.610 & 0.1810 & 68.39 & 68 \\
\hline 19 & 0.749 & 0.0636 & 69.19 & 81 \\
\hline 20 & 0.830 & 0.0361 & 70.44 & 87 \\
\hline 21 & 0.867 & 0.0274 & 69.47 & 92 \\
\hline 22 & 0.889 & 0.0235 & 69.64 & 95 \\
\hline 23 & 0.926 & 0.0209 & 70.44 & 97 \\
\hline 24 & 0.931 & 0.0179 & 70.30 & 98 \\
\hline Alcator 1 & 0.858 & 0.64 & & \\
\hline Alcator 2 & 0.465 & 0.63 & & \\
\hline Alcator 3 & 1.063 & 0.44 & & \\
\hline
\end{tabular}


CROSS SECTION OF TEST FARADAY SHIELDS
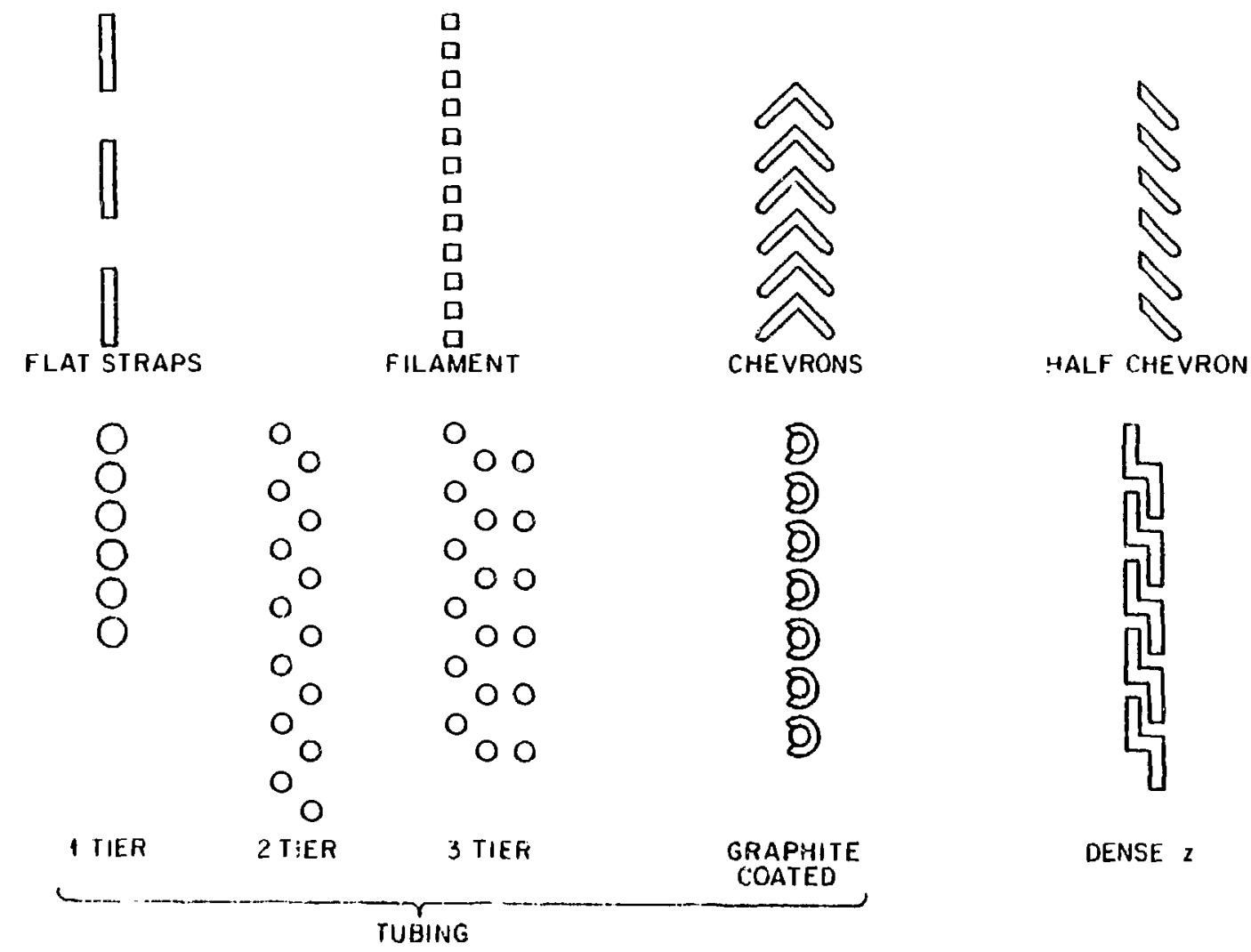

פ

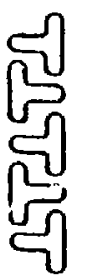

4

DENSE $z$

TEES 


\section{ALCATOR-C FARADAY SHIELD CONFIGURATION}

ORNL-OWG 85-2289 FED

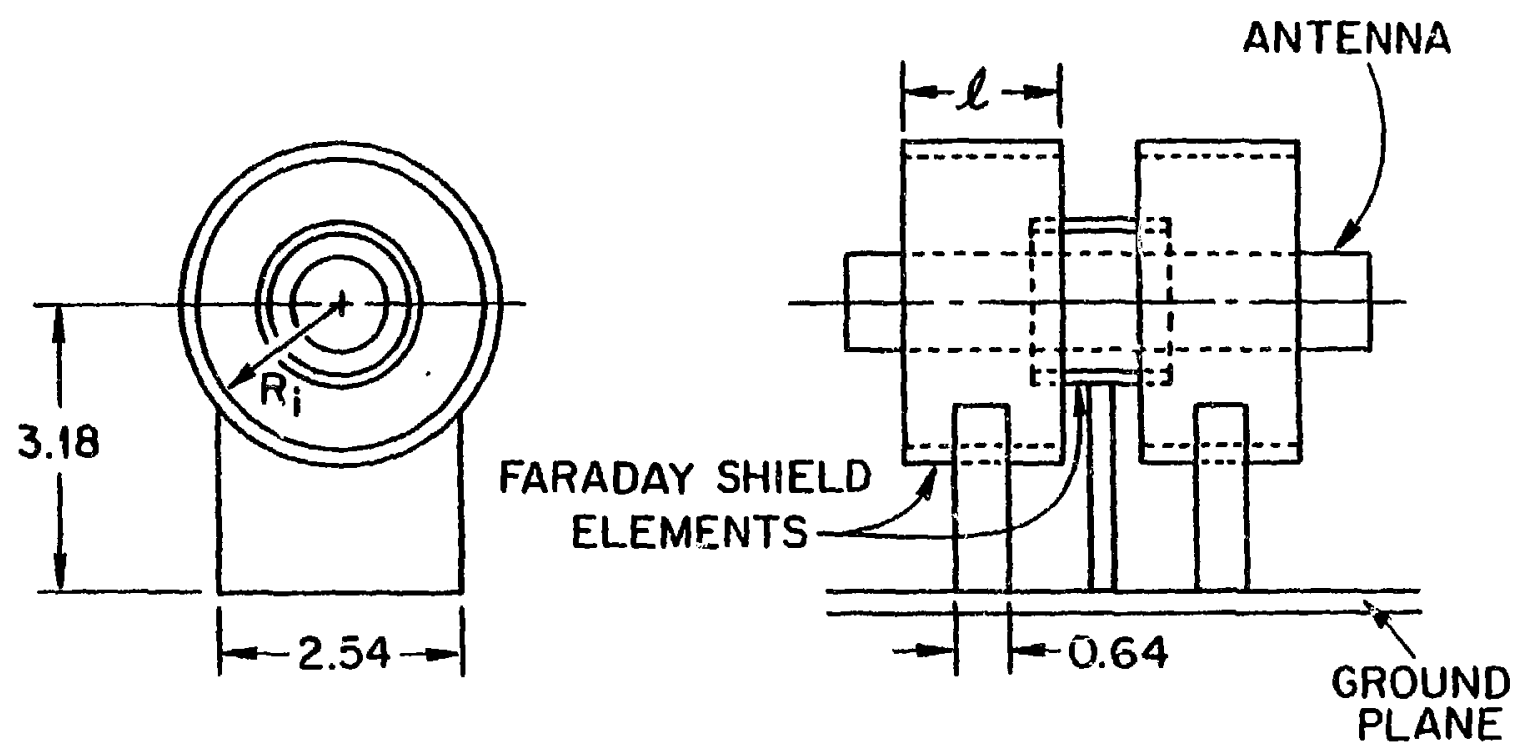

DIMENSIONS IN cm 


\section{TEST SETUP}

ORNL-DWG 85-2293 FED

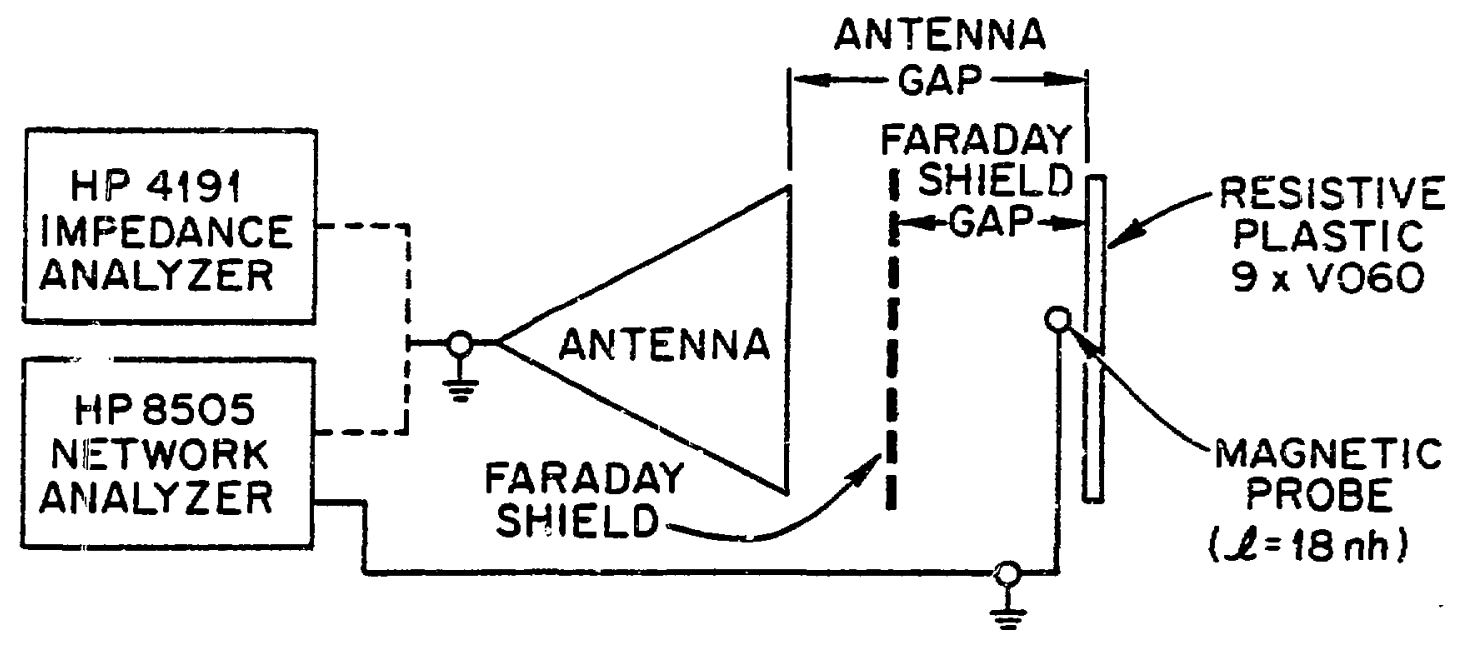




\section{CAVITY ANTENNA}

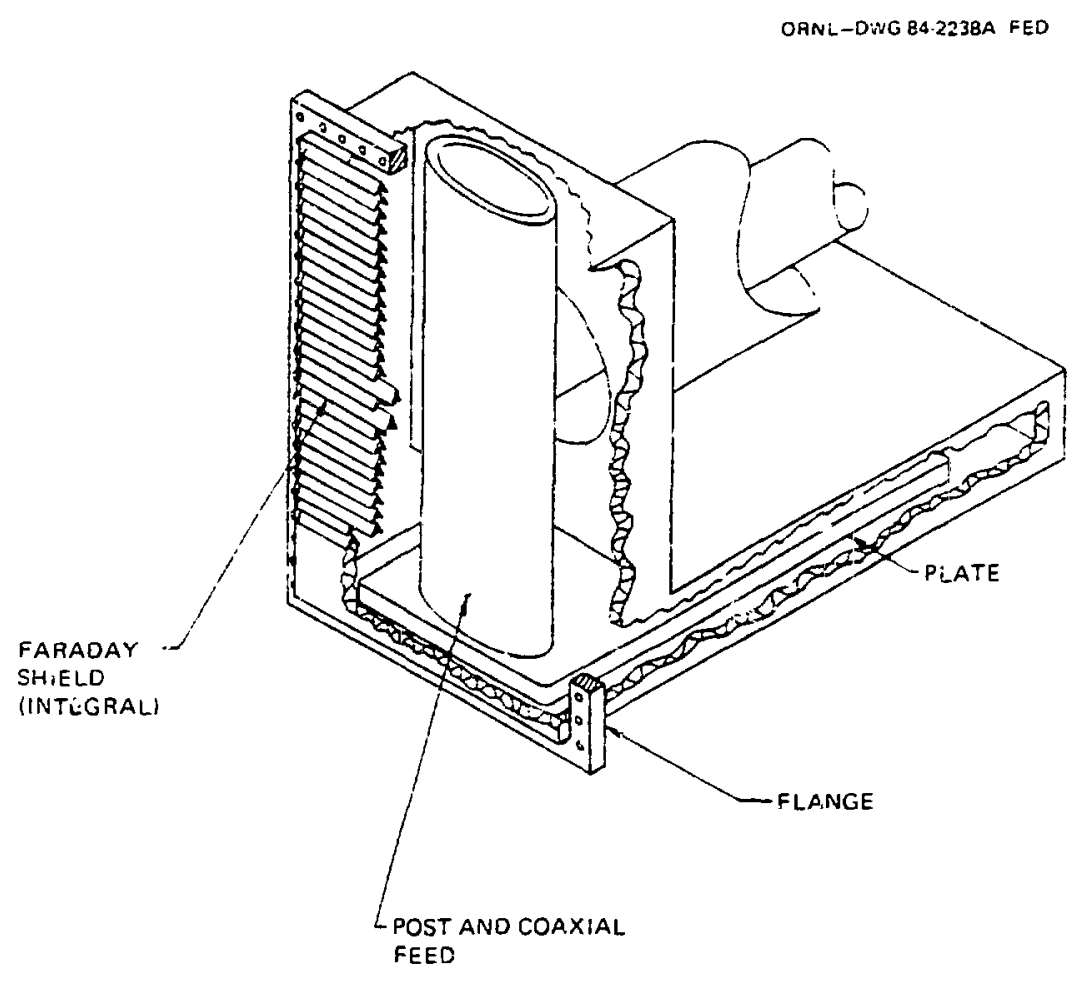


CAVITY ANTENNA

ORNL-DWG 85-2291 FED

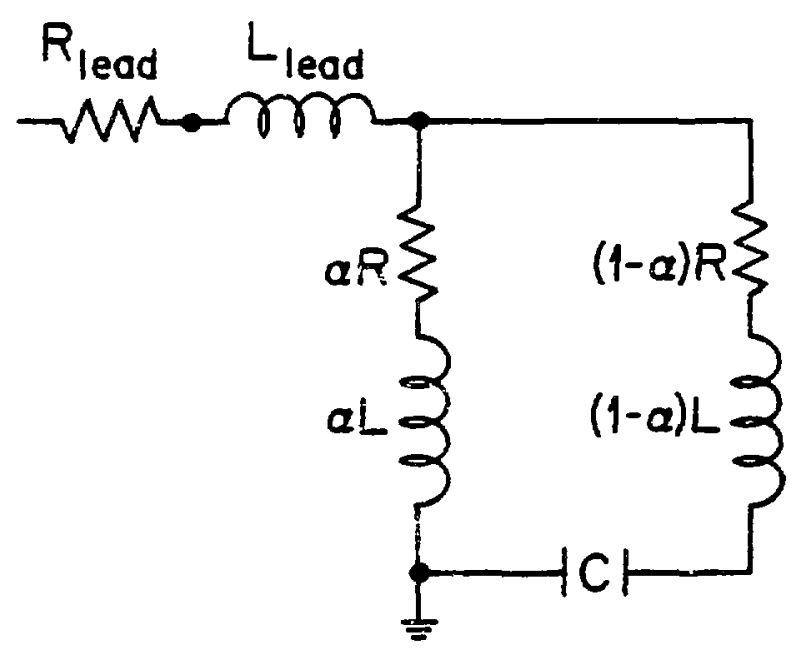

MEASUREMENTS TO INFER CIRCUIT PARAMETERS

1. INDUCTANEE AT $1 \mathrm{MHz}$

2. IMPEDANCE AT RESONANCE No. 1 AND No. 2

3. RESONANT FREQUENCY No. 1 AND No 2

4. REFLECTION COEFFIEIENT FROM 50 TO $70 \mathrm{MHz}$ 


\section{COMPARISON OF MEASURED}

\section{IMPEDANCE vS PREDICTED IMPEDANCE}

ORNL-DWG 85 - 2287

FED

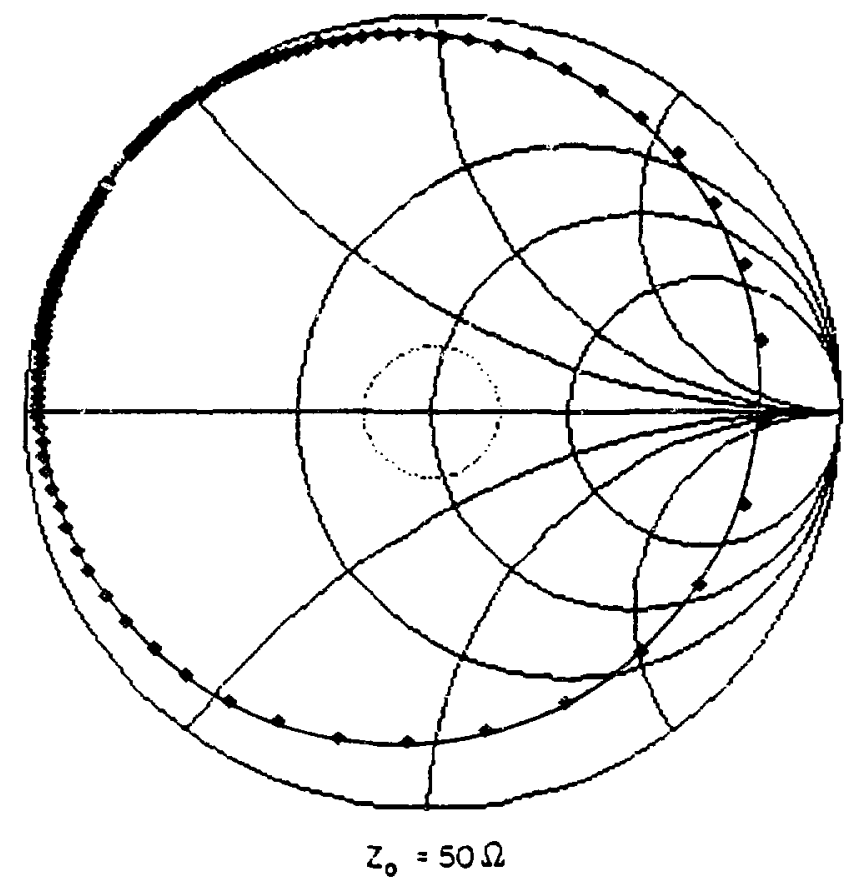

$a=0.232$

$L=71.9 \mathrm{nk}$

$L_{\text {lood }}=33 \mathrm{nh}$

$\mathrm{C}=406 \mathrm{pF}$

$R=77.5 \mathrm{~m} \Omega$

$f_{\text {min }}=50 \mathrm{MHz}$

$f_{\max }=70 \mathrm{MHz}$ 


\section{COMPARISON OF PROFILES WITH/WITHOUT \\ FARARY SHIELD}

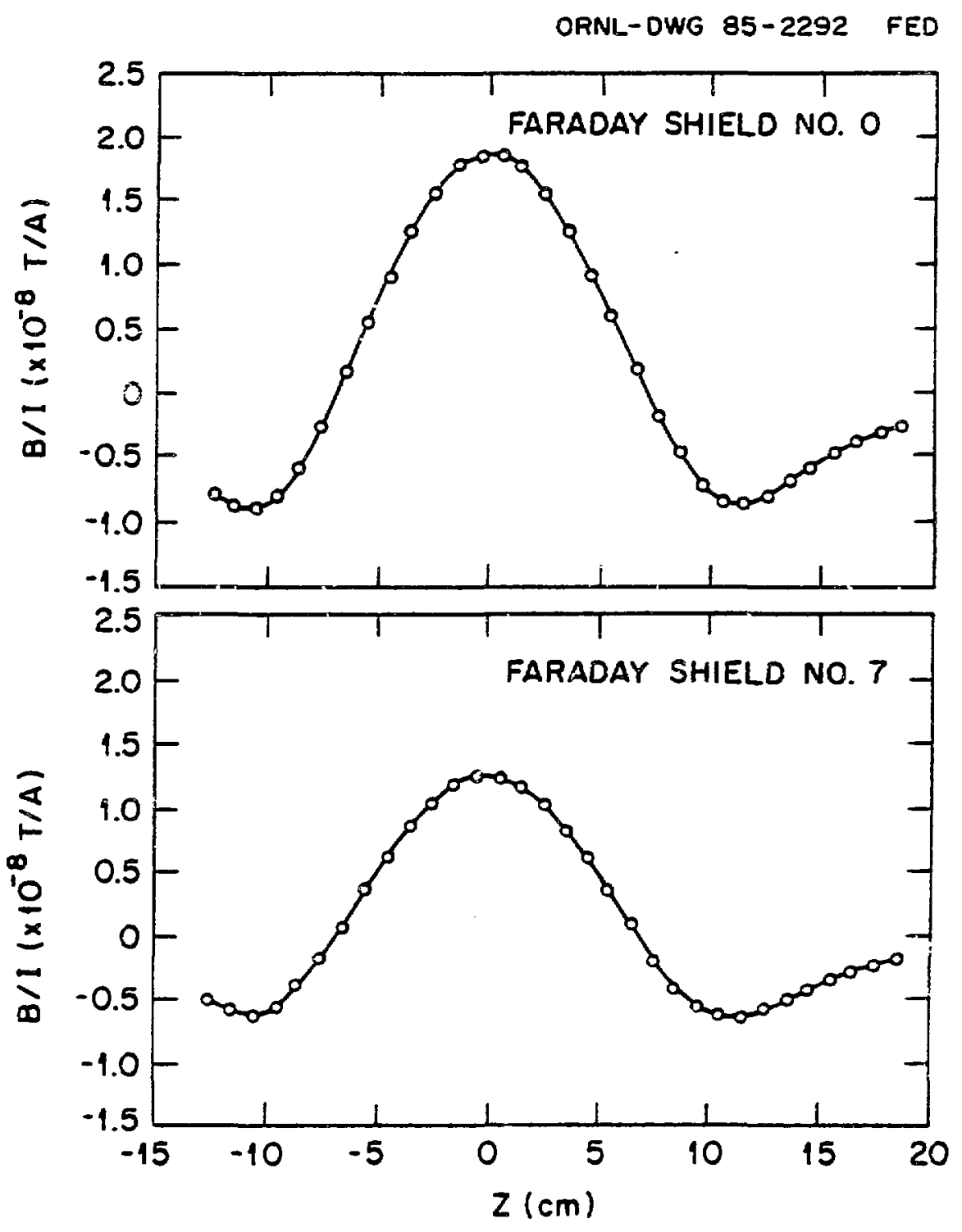




\section{DECAY OF THE RF MAGNETIC FIEL.D AWAY FROM THE ANTENNA}

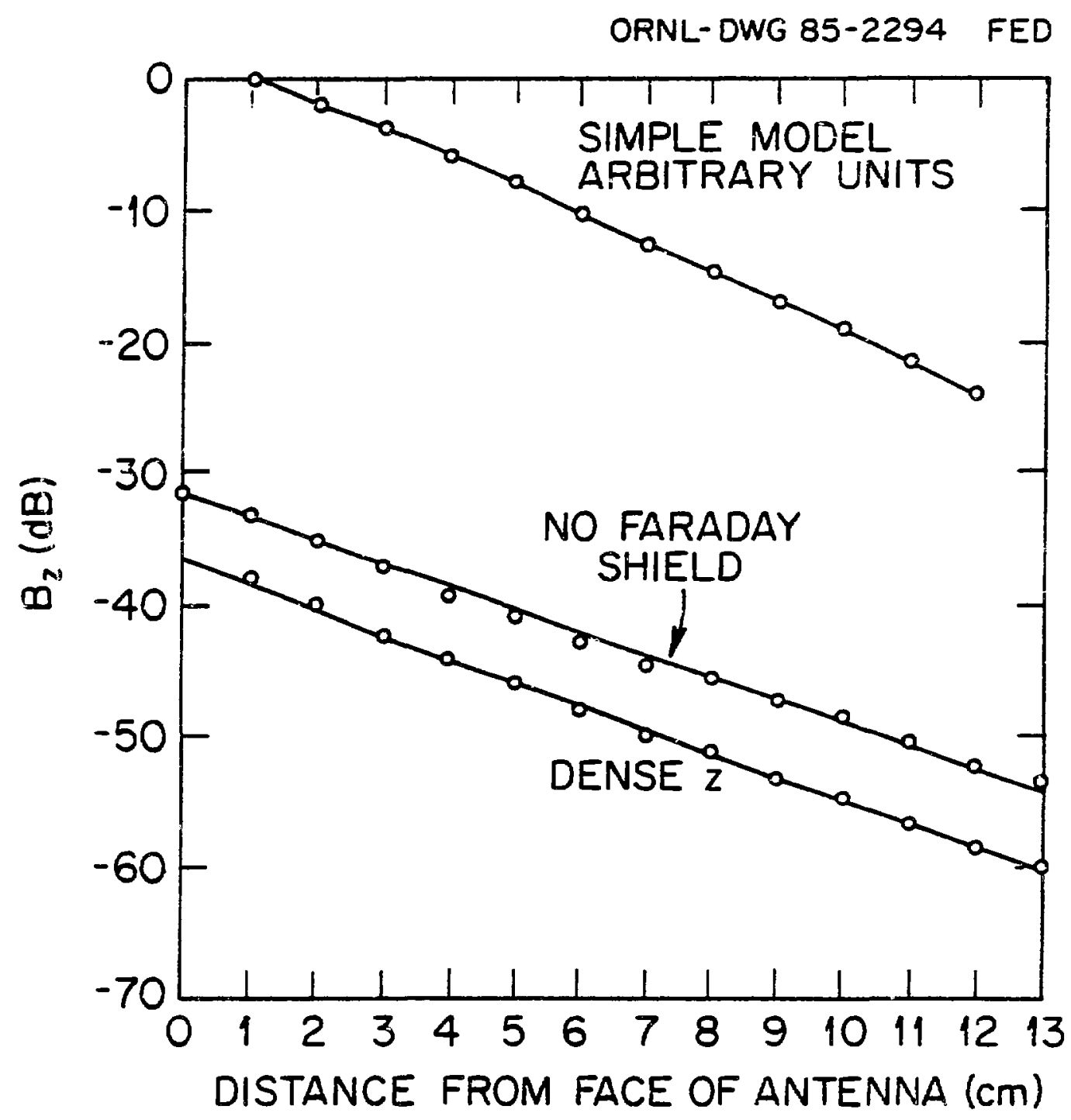


OBSERVED FLUX LINKAGE VS TOTAL RESIS TIVE LOAD

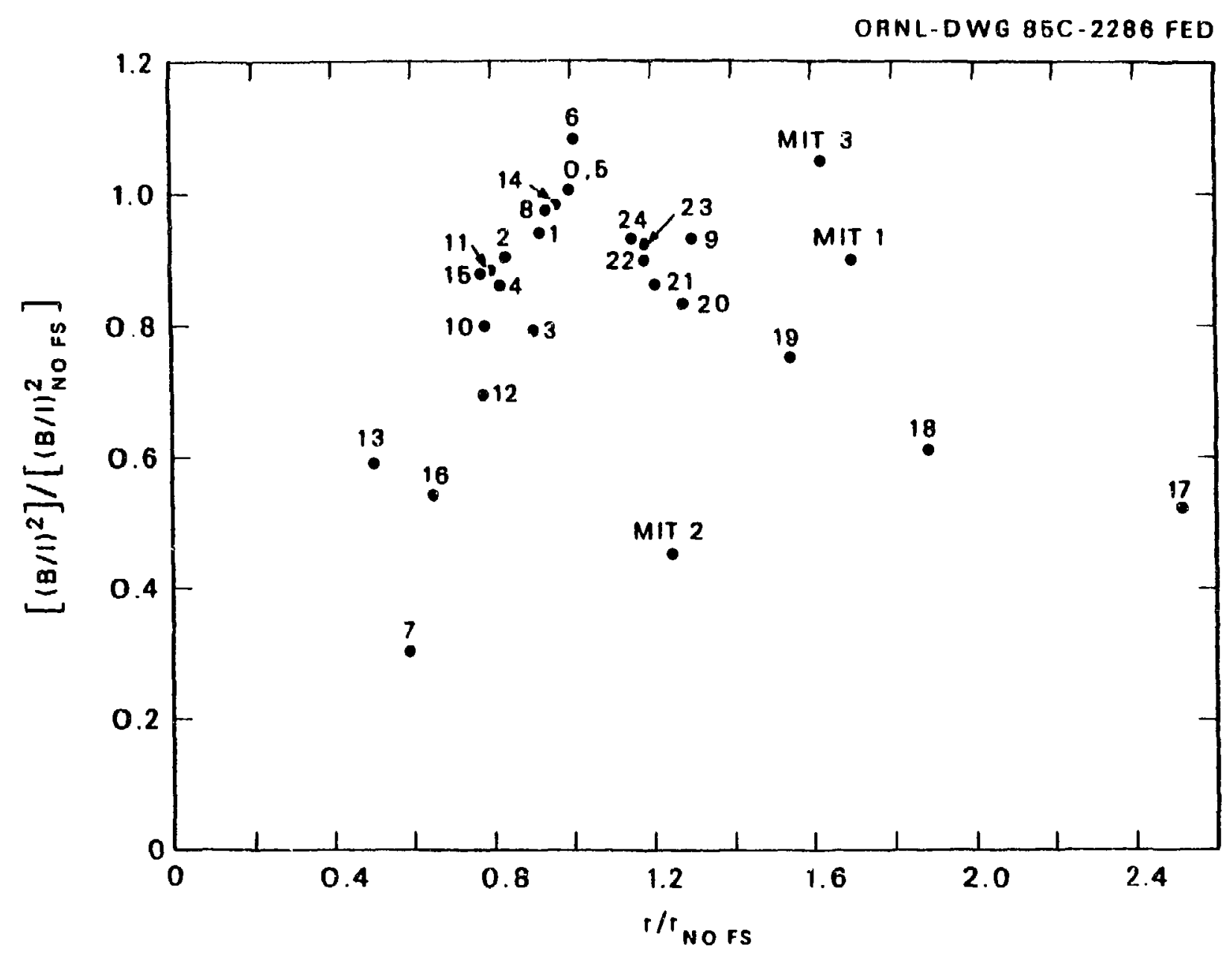




\section{MAGNETIC CONDUCTION $\left(B / /^{2}\right)$ vs GAP IN FARADAY SHIELD ELEMENTS}

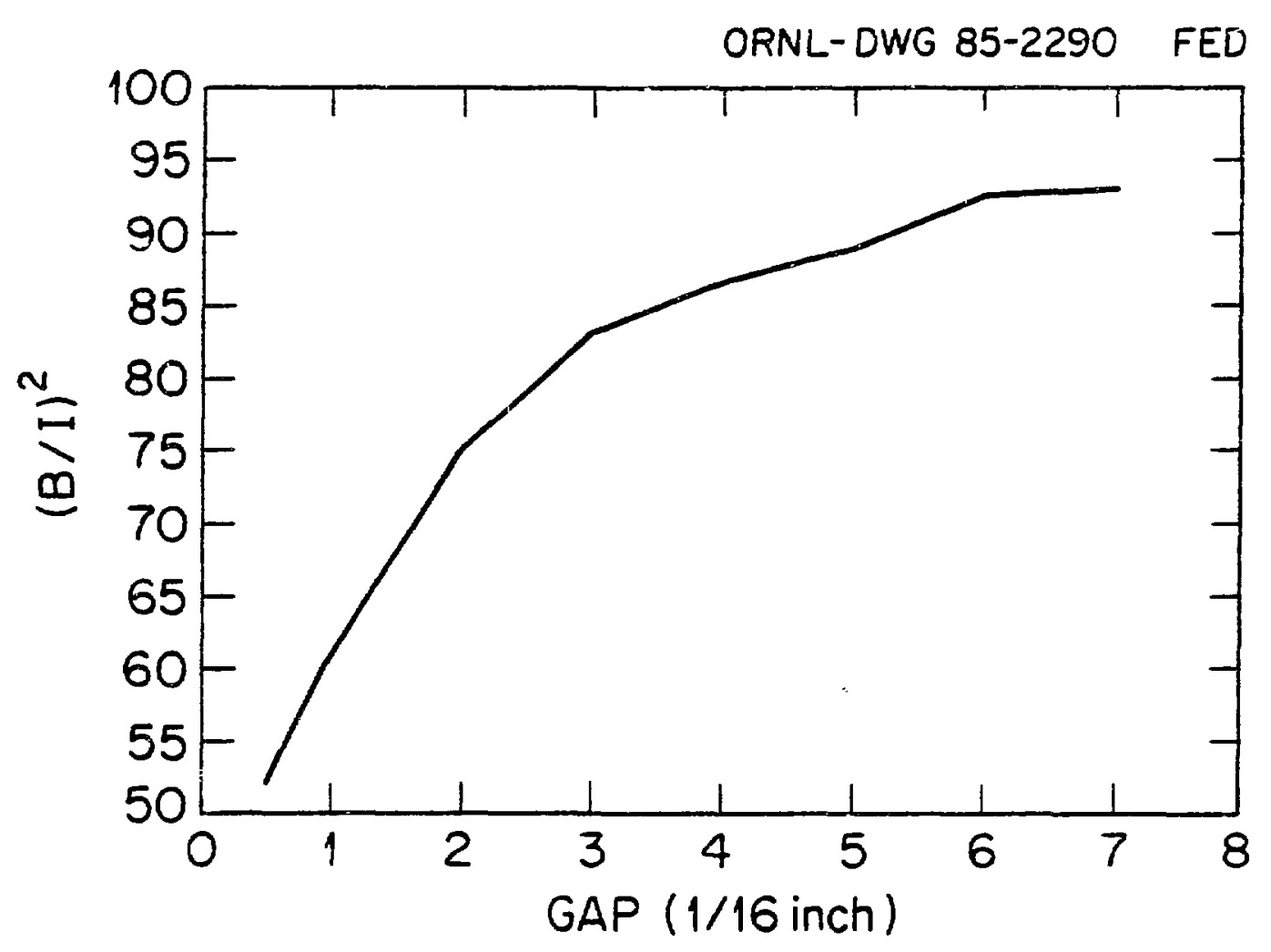

